Check for updates

Cite this: RSC Adv., 2019, 9, 25034

Received 12th May 2019

Accepted 2nd August 2019

DOI: 10.1039/c9ra03563j

rsc.li/rsc-advances

\section{Regiospecific synthesis of polysubstituted furans with mono- to tricarboxylates from various sulfonium acylmethylides and acetylenic esters $\uparrow$}

\begin{abstract}
Jun Dong, Hongguang Du (D) and Jiaxi Xu (D) *
Polysubstituted furans were prepared in moderate to good yields from various sulfur ylides and alkyl acetylenic carboxylates. The direct reactions of dimethylsulfonium acylmethylides with dialkyl acetylenedicarboxylates afforded dialkyl furan-3,4-dicarboxylates through a tandem sequence of Michael addition, intramolecular nucleophilic addition, $4 \pi$ ring opening, intramolecular Michael addition, and elimination. The method was extended to synthesize furan-3-carboxylate, -2,4-dicarboxylates, and -2,3,4-tricarboxylates as well. The current method provides a direct and simple strategy in the synthesis of structurally diverse polysubstituted furans with mono to tricarboxylate groups from safe and readily available dimethylsulfonium acylmethylides and different alkyl acetylenic carboxylates.
\end{abstract}

\section{Introduction}

Furan derivatives are not only important building blocks in organic chemistry, but also natural products found in various natural sources, most in plants, algae, and microorganisms, and structural motifs in biologically drug molecules (Fig. 1). ${ }^{1}$ Polysubstituted furans represent important cores and moieties of some biological compounds as well as acting as useful intermediates in organic synthesis. ${ }^{2}$ The development of efficient methods for their preparation has been an important research area in organic chemistry.

Historically, the classical approaches such as Paal-Knorr and Feist-Benary syntheses of furan derivatives have been widely applied. The Paal-Knorr method relies on an acidcatalyzed intramolecular cyclization of 1,4-dicarbonyl compounds, ${ }^{3}$ while the Feist-Benary method provides a strategy for the efficient preparation of polysubstituted furan derivatives via intermolecular annulation of $\beta$-dicarbonyl compounds and $\alpha$-haloketones. ${ }^{4}$ In the past few decades, many efforts for the synthesis of polysubstituted furans have been made to explore the annulation of alkynes and other unsaturated compounds.

Such as, oxazoles, 1,3,4-oxadiazoles, and furobenzopyran undergo inter- or intramolecular Diels-Alder/retro-Diels-Alder reactions with electron-poor alkynes to generate polysubstituted furans. ${ }^{5}$ The addition/oxidative cyclization of alkyl

State Key Laboratory of Chemical Resource Engineering, Department of Organic Chemistry, College of Chemistry, Beijing University of Chemical Technology, Beijing 100029, People's Republic of China. E-mail: jxxu@mail.buct.edu.cn

$\dagger$ Electronic supplementary information (ESI) available: Analytic data and copies of ${ }^{1} \mathrm{H}$ and ${ }^{13} \mathrm{C}$ NMR spectra of furan products 3 , and copies of HR-MS spectra of unknown furan products 3. See DOI: 10.1039/c9ra03563j alkynoates with carbonyl compounds in the presence of metal leads to polysubstituted furans as well. ${ }^{6}$

Sulfur ylides (sulfonium and sulfoxonium methylides) have been used as universal synthetic precursors for various chemical transformations. ${ }^{7}$ The reactions of sulfur ylides and alkynes were also applied in the synthesis of furan derivatives. One interesting and powerful method to construct the furan motif was designed through the precious metal gold-catalyzed addition of sulfur ylides to terminal alkynes in an inter- or intramolecular reaction. The reactions were the electrophilic addition of metal gold-carbenes to electron-rich alkynes (Scheme 1(I)). ${ }^{8}$ Another method for the synthesis of furan derivatives was the reaction of sulfonium ylides with dialkyl acetylenedicarboxylates. The reactive intermediate sulfonium acylmethylides were trapped by acetylenic esters to yield substituted furans in an inter- or intramolecular reaction. ${ }^{9}$ Mostly, furan-2,3-dicarboxylic acid derivatives were obtained with this method ${ }^{\mathbf{1 0}}$ and only two examples were reported on the synthesis of furan-3,4-dicarboxylic acid derivatives (Scheme 1(II)). ${ }^{11}$ We, herein, report the regioselective synthesis of

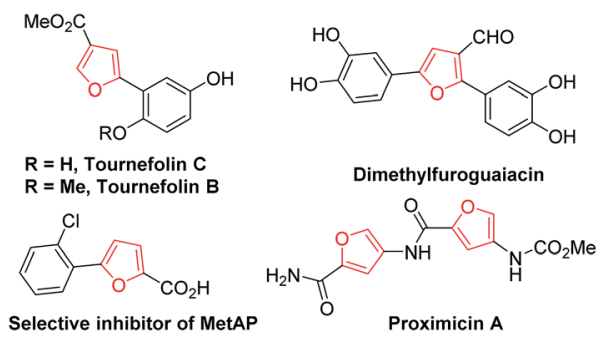

Fig. 1 Furan-derived natural products and drugs. 
Previous work:

I. Gold-Catalyzed reactions of terminal alkynes and sulfur ylides

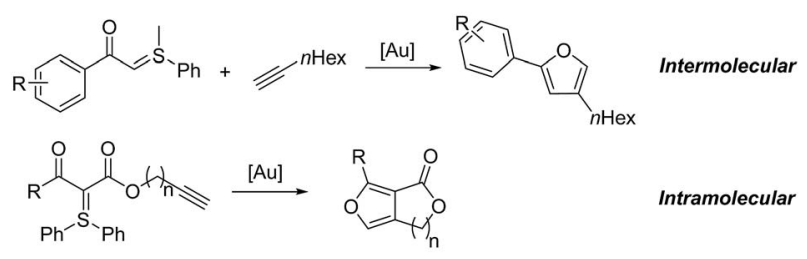

II. Metal-free reactions of electron-deficient alkynes and sulfur ylides

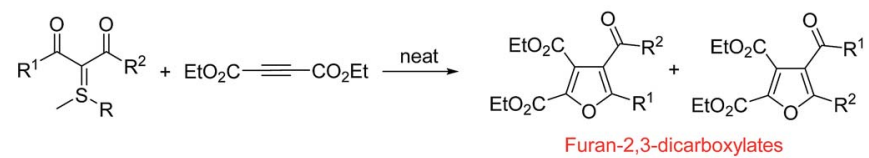

$$
\prod_{-\mathrm{S} \backslash}^{\mathrm{O}} \mathrm{R}+\mathrm{MeO}_{2} \mathrm{C}=\mathrm{CO}_{2} \mathrm{Me} \stackrel{\mathrm{DMSO}}{\longrightarrow} \underbrace{\mathrm{MeO}_{2} \mathrm{C}}_{\text {Furan-3,4-dicarboxylates }}
$$

III. The current work:

$$
\|_{S}^{R^{2}}+\mathrm{RO}_{2} \mathrm{C}=\mathrm{EWG} \frac{80^{\circ} \mathrm{C} \text { or } 160^{\circ} \mathrm{C}}{\mathrm{DMSO}, \mathrm{N}_{2}}
$$

$\mathrm{R}^{1}=\mathrm{Ar}, \mathrm{Me}, \mathrm{R}^{2}=\mathrm{H}, \mathrm{CO}_{2} \mathrm{Et}, \mathrm{CO}_{2} \mathrm{Me}$; $\mathrm{CO}_{2} \mathrm{R}=\mathrm{CO}_{2} \mathrm{Me}, \mathrm{CO}_{2} \mathrm{Et}$;

$\mathrm{EWG}=\mathrm{CO}_{2} \mathrm{Me}, \mathrm{CO}_{2} \mathrm{Et}, \mathrm{CF}_{3}$

Scheme 1 Synthesis of polysubstituted furans from sulfur ylides and alkynes.

structurally diverse polysubstituted furans with mono to tricarboxylates from various acetylenic esters and dimethylsulfonium acylmethylides and the mechanistic rationale on the selective generation of dialkyl furan-3,4-dicarboxylates.

\section{Results and discussion}

To understand the mechanism and to explore the substrate scope of the reaction of dialkyl acetylenedicarboxylates and dimethylsulfonium acylmethylides, dimethyl acetylenedicarboxylate (DMAD) (1a) and 2-(dimethyl- $\lambda^{4}$-sulfanylidene)-1phenylethan-1-one (dimethylsulfonium benzoylmethylide) (2a) were employed as the model substrates to optimize the reaction conditions in 1,2-dichloroethane (DCE) under nitrogen atmosphere. We first optimized the reactant ratio (Table 1, entries 13). When the ratio of $1 \mathrm{a}: 2 \mathrm{a}$ was increased from $1: 2$ to $1: 2.4$, the yield of product dimethyl 2-phenylfuran-3,4-dicarboxylate (3aa) decreased from $44 \%$ to $34 \%$ (Table 1, entries 1 and 2). The yield dropped sharply to $15 \%$ when the ratio of $1 \mathbf{a}: \mathbf{2 a}$ was $2: 1$ (Table 1, entry 3). Solvents were also screened. Product 3aa was obtained in $57 \%$ in polar DMF as solvent (Table 1, entry 4). The reactions with MeCN and DMSO as solvents gave product 3aa in $50 \%$ and $81 \%$ yields, respectively (Table 1, entries 5 and 6). The results indicated that DMSO was the best choice. The yield decreased to $70 \%$ when the reaction was conducted without nitrogen protection (Table 1, entry 7). It was found that the extension of the reaction time had no significant effect on the yield of product 3aa (Table 1, entry 8). When the reaction time was shortened from $4 \mathrm{~h}$ to $2 \mathrm{~h}$, the yield was slightly dropped to $73 \%$ (Table 1, entry 6 vs. 9). At last, the yield of product 3aa was $80 \%$ when the reaction was conducted at $110{ }^{\circ} \mathrm{C}$ (Table 1 , entry 10$)$.

With the optimized reaction conditions, the reaction scope was then evaluated (Table 2). Various sulfonium ylides 2 were examined in the reaction with dimethyl acetylenedicarboxylate (DMAD) (1a). We were pleased to find that the application of various sulfonium ylides 2 led to the corresponding furan-3,4dicarboxylates 3 in moderate to good yields. Various functional groups such as methyl, fluoro, chloro, bromo, trifluoromethyl, and cyano on the aryl group of the sulfur ylides 2 were well tolerated under optimized reaction conditions (Table 2 , 3ab-3ah). For electron-deficient 2-(dimethyl- $\lambda^{4}$ sulfanylidene)-1-(4-nitrophenyl)ethan-1-one (2i), the desired furan-3,4-dicarboxylate 3ai was isolated in $45 \%$ yield under the optimized reaction conditions. In comparison with dimethylsulfonium monosubstituted benzoylmethylides $2 \mathbf{a}-\mathbf{2} \mathbf{i}$, the sulfur ylide with more substituted on the aryl group was tested as well. 1-(3,4-Dichlorophenyl)-2-(dimethyl- $\lambda^{4}$-sulfanylidene) ethan-1-one (1j) gave rise to the corresponding furan-3,4dicarboxylate 3 aj in $74 \%$ yield. After replacing the phenyl group with naphthyl, the corresponding products 3ak and 3al were obtained in $85 \%$ and $75 \%$ yields, respectively. After investigating the reaction of different dimethylsulfonium 2-aryl2-oxoethylides 2 with dimethyl acetylenedicarboxylate, diethyl acetylenedicarboxylate (1) $)$ was evaluated with three representative sulfur ylides $\mathbf{2 a}, \mathbf{2} \mathbf{b}, \mathbf{2} \mathbf{2}$, affording the desired products $\mathbf{3} \mathbf{b a}$, $3 \mathrm{bb}$, and $3 \mathbf{b f}$ in $56 \%, 53 \%$, and $68 \%$ yields, respectively, under the optimized reaction conditions.

To extend the application of the synthetic method, several alkyl propynoates were attempted to prepare alkyl 2-substituted furan-3-carboxlyates (Table 2). Gratifyingly, ethyl 4,4,4-

Table 1 Screening of reaction conditions ${ }^{a}$

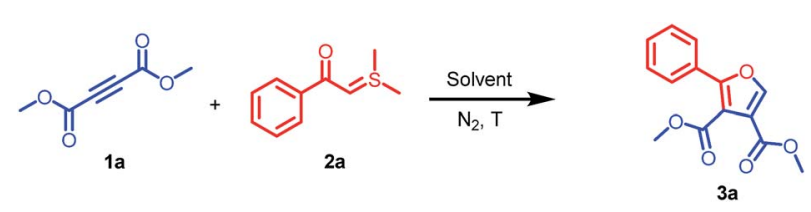

\begin{tabular}{lllll}
\hline Entry & $1 \mathbf{a}: \mathbf{2 a}$ & Solvent & Time $(\mathrm{h})$ & ${\text { Yield }(\%)^{b}}^{b}$ \\
\hline 1 & $1: 2$ & DCE & 4 & 44 \\
2 & $1: 2.4$ & DCE & 4 & 34 \\
3 & $2: 1$ & DCE & 4 & 15 \\
4 & $1: 2$ & DMF & 4 & 57 \\
5 & $1: 2$ & MeCN & 4 & 50 \\
6 & $1: 2$ & DMSO & 4 & $81(79)^{c}$ \\
7 & $1: 2$ & DMSO & 4 & $70^{d}$ \\
8 & $1: 2$ & DMSO & 6 & 80 \\
9 & $1: 2$ & DMSO & 2 & 73 \\
$10^{e}$ & $1: 2$ & DMSO & 4 & 80
\end{tabular}

${ }^{a}$ All reactions were conducted on a $0.125 \mathrm{mmol}$ scale of $1 \mathrm{a}$ in $1 \mathrm{~mL}$ of solvent at $80{ }^{\circ} \mathrm{C}$. ${ }^{b} \mathrm{NMR}$ yield of the crude product using 1,3,5trimethoxybenzene as an internal standard. ${ }^{c}$ Yield of the isolated product. ${ }^{d}$ Without nitrogen protection. ${ }^{e}$ The reaction conducted at $110{ }^{\circ} \mathrm{C}$. 
Table 2 Synthesis of polysubstituted furans from various alkyl acetylenic esters and sulfur ylides ${ }^{a}$
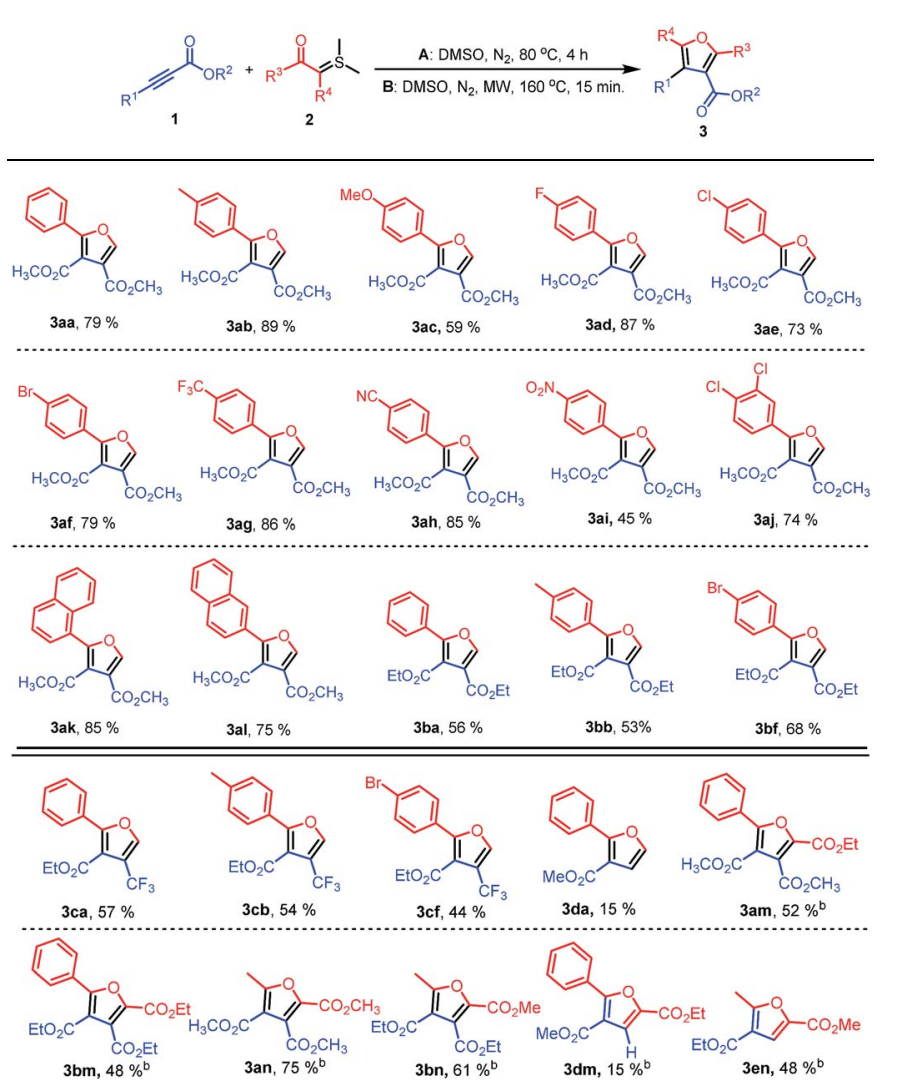

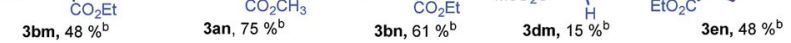

${ }^{a}$ Reaction conditions A: acetylenic ester $\mathbf{1}(0.125 \mathrm{mmol})$ and sulfur ylide $2(0.250 \mathrm{mmol})$ in DMSO $(1 \mathrm{~mL})$ were stirred under nitrogen at $80^{\circ} \mathrm{C}$ for 4 h. ${ }^{b}$ Reaction conditions B: acetylenic ester $1(0.125 \mathrm{mmol})$ and sulfur ylide $2(0.250 \mathrm{mmol})$ in DMSO $(1 \mathrm{~mL})$ were stirred under nitrogen at $160{ }^{\circ} \mathrm{C}$ for 15 min under microwave irradiation.

trifluorobut-2-ynoate (1c) was also successful for the synthesis of the corresponding trifluoromethylated furan-3-carboxylate derivatives. The desired 4-trifluoromethylfuran-3-carboxylates 3ca-3cf were obtained in moderate yields of $44-57 \%$. However, methyl propynoate (1d) only produced the corresponding furan-3-carboxylate $3 \mathrm{da}$ in a low yield of $15 \%$ when it was reacted with sulphur ylide 2 a.

Further extension of the synthetic strategy in the preparation of trialkyl furan-2,3,4-tricarboxylates was performed (Table 2). It was worth noting that no desired products were observed for diacyl stabilized sulfonium ylides $2 \mathbf{m}$ and $2 \mathbf{n}$ at $80^{\circ} \mathrm{C}$ when they were applied in the reaction. To our delight, the desired trialkyl furan-2,3,4-tricarboxylates $\mathbf{3 a m}, \mathbf{3} \mathbf{b m}$, 3an, and $\mathbf{3} \mathbf{b n}$ were obtained in moderate to good yields of $48 \%$ to $75 \%$ when the reaction temperature was increased from $80^{\circ} \mathrm{C}$ to $160^{\circ} \mathrm{C}$ under microwave irradiation due to the microwave assistance. ${ }^{11,12}$

Finally, the synthetic strategy was tested in the preparation of dialkyl furan-2,4-dicarboxylates as well (Table 2). The reaction of diacyl stabilized sulfonium ylide $\mathbf{2 m}$ and methyl propynoate (1d) afforded the desired furan-2,4-dicarboxylate $\mathbf{3 d m}$ in a low yield of $15 \%$, while diacyl stabilized sulfonium ylide $2 \mathrm{n}$ reacted with ethyl propynoate (1e), giving the desired furan-2,4dicarboxylate $3 \mathrm{en}$ in a moderate yield of $48 \%$. However, in a previous report, ${ }^{10 a}$ the reaction of diacyl stabilized sulfonium ylide $\mathbf{2 n}$ and ethyl propynoate (1e) produced 2-ethyl 4-methyl 5methylfuran-2,4-dicarboxylate (4en) only in $73 \%$ yield in 1,4dioxane at $160{ }^{\circ} \mathrm{C}$, showing a different reaction regioselectivity from our results. To verify the different selectivity, we conducted the same reaction in 1,4-dioxane at $160{ }^{\circ} \mathrm{C}$ under microwave irradiation, affording a mixture of 4-ethyl 2-methyl 5methylfuran-2,4-dicarboxylate (3en) and 2-ethyl 4-methyl 5methylfuran-2,4-dicarboxylate (4en) in a ratio of $1: 1.81$ in $53 \%$ total yield. However, under our optimal conditions, only 4-ethyl 2-methyl 5-methylfuran-2,4-dicarboxylate (3en) was obtained regiospecifically in DMSO as solvent. The results revealed that solvent and temperature played important effects on the reaction pathways, resulting in regioselective formation of different furan derivatives. The exact reason for the selective control is not clear now possible it is attributed the stability of intermediates in different solvents during reaction.

The reactions of both sulfur ylides $2 \mathrm{a}$ and $\mathbf{2 m}$ with methyl propynoate (1d) gave rise to the corresponding products 3da and $\mathbf{3 d m}$ in low yields because methyl propynoate (1d) was not electron-deficient enough compared with other acetylenic esters and then it was difficult for sulfonium ylides $2 \mathbf{a}$ or $\mathbf{2 m}$ to undergo Michael addition to methyl propynoate (1d).

After obtaining the above information, we proposed the following reaction mechanism (Scheme 2). Dimethyl acetylenedicarboxylate (1a) and 2-(dimethyl- $\lambda^{4}$-sulfanylidene)-1phenylethan-1-one (2a) are used to illustrate the proposed mechanism. First, 2 -(dimethyl- $\lambda^{4}$-sulfanylidene)-1-phenylethan1-one (2a) undergoes Michael addition to dimethyl acetylenedicarboxylate (1a) to generate intermediate $\mathbf{A}$, which further takes place an intramolecular nucleophilic addition to the carbonyl group of the benzoyl group to produce zwitterionic intermediate B. The intermediate $\mathbf{B}$ undergoes a $4 \pi$ ring opening to form intermediate enolate $\mathbf{C}$. The enolate in intermediate $\mathbf{C}$ takes place an intramolecular Michael addition followed by the elimination of dimethyl sulfide to give furan 3aa. In the previous report, ${ }^{11}$ the conversion of intermediates $\mathbf{A}$ to $\mathbf{C}$ was assumed as the benzoyl group shift followed by tautomerization. In our viewpoint, it is an intramolecular nucleophilic addition followed by a $4 \pi$ ring opening process. This is a more reasonable conversion pathway.

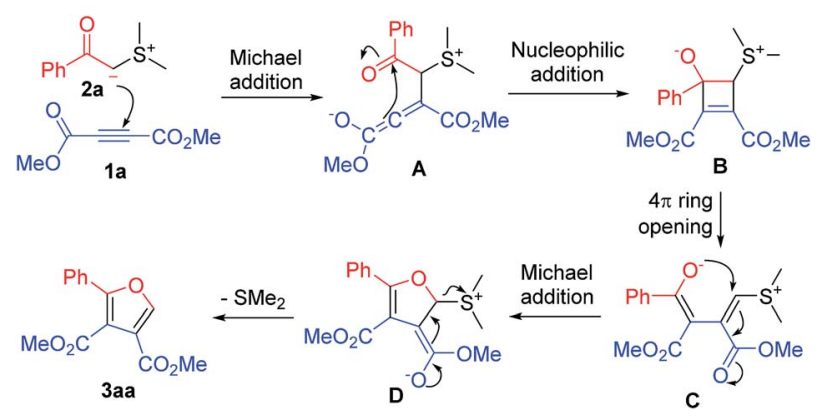

Scheme 2 Proposed reaction mechanism. 

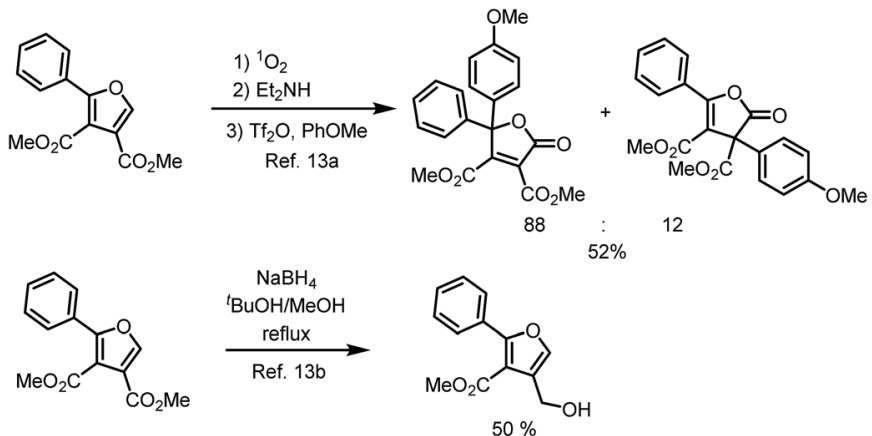

Scheme 3 Selected reported application.

Selected applications of polysubstituted furans, dimethyl 2phenylfuran-3,4-dicarboxylates, from the literature are listed in Scheme $3,{ }^{13}$ One for synthesis of diaryldihydrofuranones, ${ }^{13 a}$ the other for furanmethanol. ${ }^{13 b}$

\section{Conclusions}

Polysubstituted furans with carboxylate(s) were prepared in moderate to good yields from dimethylsulfonium acylmethylides with alkyl acetylenecarboxylates through a tandem sequence of Michael addition, intramolecular nucleophilic addition, $4 \pi$ ring opening, intramolecular Michael addition, and elimination. The current method provides a direct and simple strategy in the efficient preparation of dialkyl 2substituted furan-3,4-dicarboxylates from safe and readily available dimethylsulfonium acylmethylides and dialkyl acetylenedicarboxylates. In addition, the current method can also be applied for the synthesis of alkyl 2-arylfuran-3-carboxylates, dialkyl 5-substituted furan-2,4-dicarboxylates, and trialkyl 5substituted furan-2,3,4-tricarboxylates, even alkyl 4trifluoromethylfuran-3-carboxylates, showing versatile application. A new reasonable reaction mechanism is proposed as well.

\section{Experimental}

Unless otherwise noted, all materials were purchased from commercial suppliers. Flash column chromatography was performed using silica gel (normal phase, 200-300 mesh) from Branch of Qingdao Haiyang Chemical Industry. The petroleum ether (PE) used for column chromatography is the $60-90{ }^{\circ} \mathrm{C}$ fraction, and the removal of residue solvent was accomplished under rotovap. The reactions were monitored by thin-layer chromatography (TLC) on silica gel GF254 coated $0.2 \mathrm{~mm}$ plates from Institute of Yantai Chemical Industry. The plates were visualized under UV light, as well as the other TLC stains (10\% phosphomolybdic acid in ethanol; $1 \%$ potassium permanganate in water; $10 \mathrm{~g}$ of iodine absorbed on $30 \mathrm{~g}$ of silica gel). ${ }^{1} \mathrm{H}$ and ${ }^{13} \mathrm{C}$ NMR spectra were recorded on a Bruker 400 $\mathrm{MHz}$ spectrometer in $\mathrm{CDCl}_{3}$ with TMS as an internal standard, and the chemical shifts $(\delta)$ are reported in parts per million (ppm). All coupling constants $(J)$ in ${ }^{1} \mathrm{H}$ NMR spectra are absolute values given in hertz $(\mathrm{Hz})$ with peaks labelled as singlet $(\mathrm{s})$, broad singlet (brs), doublet (d), triplet ( $\mathrm{t})$, quartet (q), and multiplet $(\mathrm{m})$. The IR spectra ( $\mathrm{KBr}$ pellets, $v\left[\mathrm{~cm}^{-1}\right]$ ) were recorded on a Nicolet 5700 FTIR spectrometer. HRMS measurements were carried out on an Agilent LC/MSD TOF mass spectrometer. LRMS measurements were carried out on a Thermo Trace 1300/ISQ QD system. Melting points were obtained on a Yanaco MP-500 melting point apparatus and are uncorrected. All the microwave reactions were conducted in a CEM Discover SP microwave system equipped with an infrared temperature detector.

\section{General procedure for the synthesis of sulfur ylides $2 a-21$}

To a solution of halomethyl carbonyl compound $4(10 \mathrm{mmol})$ in acetone $(15 \mathrm{~mL})$ was added dimethyl sulfide $(620 \mathrm{mg}, 10 \mathrm{mmol})$. After the mixture was stirred for $12 \mathrm{~h}$, the residue was filtered and washed with acetone. The solid product was used as sulfonium halide without further purification. The corresponding sulfonium halide was added to a solution of $\mathrm{NaOH}$ $(400 \mathrm{mg}, 10 \mathrm{mmol})$ in water $(10 \mathrm{~mL})$ at $0{ }^{\circ} \mathrm{C}$. The solution was stirred for $30 \mathrm{~min}$ and then extracted several times with dichloromethane. The combined organic layers were washed with water and brine sequentially, dried over $\mathrm{Na}_{2} \mathrm{SO}_{4}$, filtered, and concentrated. The sulfur ylide 2 was obtained and can be used directly without further purification.

\section{General procedure for the synthesis of sulfur ylides $2 \mathrm{~m}$ and $2 n^{14}$}

To a suspension of NCS $(3.472 \mathrm{~g}, 26 \mathrm{mmol})$ in anhydrous dichloromethane $(110 \mathrm{~mL})$ was added dimethyl sulfide $(2.7 \mathrm{~mL}$, $36.9 \mathrm{mmol})$ at $-78{ }^{\circ} \mathrm{C}$ under nitrogen. The mixture was stirred for $1 \mathrm{~h}$ at the same temperature. A solution of an active methylene compound ( $20 \mathrm{mmol}$ ) was added at the same temperature. After addition of triethylamine $(4.2 \mathrm{~mL}, 30.3 \mathrm{mmol})$, the resulting mixture was stirred for another $1 \mathrm{~h}$. The reaction mixture was treated with cold brine $(60 \mathrm{~mL})$ and extracted with ether $(180 \mathrm{~mL})$. The organic layer was washed with brine $(60 \mathrm{~mL})$ three times, dried over $\mathrm{Na}_{2} \mathrm{SO}_{4}$, filtered, and concentrated. The residue was purified by column chromatography with chloroform and methanol $(20: 1, \mathrm{v} / \mathrm{v})$ as eluent to afford the desired yilde $\mathbf{2 m}$ or $\mathbf{2 n}$.

\section{General procedure for the synthesis of furan derivatives 3}

Reaction conditions A. To a stirred suspension of sulfur ylide $2(0.25 \mathrm{mmol})$ in DMSO $(1 \mathrm{~mL})$ was added acetylenic ester 1 $(0.125 \mathrm{mmol})$. The mixture was further stirred at $80{ }^{\circ} \mathrm{C}$ for 4 hours under nitrogen. After cooling and addition of water (10 $\mathrm{mL}$ ), the mixture was extracted with DCM, and combined organic layer was washed with brine, dried over anhydrous sodium sulfate, and concentrated in vacuo. The resulting residue was purified by silica gel column chromatography with petroleum ether and ethyl acetate $(10: 1, \mathrm{v} / \mathrm{v})$ as eluent to afford furan 3.

Reaction conditions B. To a stirred suspension of sulfur ylide $2(0.25 \mathrm{mmol})$ in DMSO $(1 \mathrm{~mL})$ was added acetylenic ester 1 $(0.125 \mathrm{mmol})$. The mixture was further stirred at $160{ }^{\circ} \mathrm{C}$ for 15 min under microwave irradiation with $\mathrm{N}_{2}$ protection. After 
cooling and addition of water $(10 \mathrm{~mL})$, the mixture was extracted with DCM. The combined organic layer was washed with brine, dried over anhydrous sodium sulfate, and concentrated in vacuo. The resulting residue was purified by silica gel column chromatography with petroleum ether and ethyl acetate $(10: 1$, $\mathrm{v} / \mathrm{v}$ ) as eluent to afford furan 3.

\section{Conflicts of interest}

There are no conflicts to declare.

\section{Acknowledgements}

This work was supported partially from the National Natural Science Foundation of China (no. 21702014 and 21572017) and the Fundamental Research Funds for the Central Universities (XK1802-6).

\section{References}

1 (a) Q.-Z. Ye, S.-X. Xie, M. Huang, W.-J. Huang, J.-P. Lu and Z.-Q. Ma, J. Am. Chem. Soc., 2004, 126, 13940-13941; (b) Y.-L. Lin, Y.-L. Tsai, Y.-H. Kuo, Y.-H. Liu and M.-S. Shiao, J. Nat. Prod., 1999, 62, 1500-1503; (c) J. F. Kratochvil, R. H. Burris, M. K. Seikel and J. M. Harkin, Phytochemistry, 1971, 10, 2529-2531.

2 A. Blanc, V. Beneteau, J. M. Weibel and P. Pale, Org. Biomol. Chem., 2016, 14, 9184-9205.

3 (a) L. Knorr, Chem. Ber., 1884, 17, 2863-2870; (b) C. Paal, Chem. Ber., 1884, 17, 2756-2767.

4 (a) F. Feist, Chem. Ber., 1902, 35, 1545; (b) E. Benary, Chem. Ber., 1911, 44, 489-493.

5 (a) J. Wang, S. Luo, J. Huang, T. Mao and Q. Zhu, Chem, 2014, 20, 11220-11224; (b) E. O. Onyango and P. A. Jacobi, J. Org. Chem., 2012, 77, 7411-7427; (c) T. Aoyama, Y. Hari and T. Iguchi, Synthesis, 2004, 1359-1362; (d) P. C. Ducepta and S. P. Marsden, ARKIVOC, 2002, 22-34; (e) G. E. Daia, C. D. Gabbutt, J. D. Hepworth, B. M. Heron, D. E. Hibbs and M. B. Hursthouse, Tetrahedron Lett., 2002, 43, 45074510; $(f)$ W. Pei, J. Pei, S. Li and X. Ye, Synthesis, 2000, 2069-2077; (g) T. Ibata and K. Fukushima, Chem. Lett., 1992, 21, 2197-2200; (h) H. Gotthardt, R. Huisgen and H. O. Bayer, J. Am. Chem. Soc., 1970, 92, 4340-4344.

6 (a) Z. Luo, Y. Fang, Y. Zhao, P. Liu, X. Xu, C. Feng, Z. Li and J. He, RSC Adv., 2016, 6, 5436-5441; (b) S. Manna and A. P. Antonchick, Org. Lett., 2015, 17, 4300-4303; (c) W.-B. Liu, C. Chen and Q. Zhang, Synth. Commun., 2013, 43, 951-960; (d) W. Liu, H. Jiang, M. Zhang and C. Qi, J. Org. Chem., 2010, 75, 966-968; (e) Y. Liang, G. Huang,
R. Yan, J. Huang, J. Luo and P. Wen, Synlett, 2010, 10711074.

7 (a) L. Q. Lu, T. R. Li, Q. Wang and W. J. Xiao, Chem. Soc. Rev., 2017, 46, 4135-4149; (b) A. C. B. Burtoloso, R. M. P. Dias and I. A. Leonarczyk, Eur. J. Org. Chem., 2013, 5005-5016; (c) V. K. Aggarwal and C. L. Winn, Acc. Chem. Res., 2004, 37, 611-620; (d) A. H. Li, L. X. Dai and V. K. Aggarwal, Chem. Rev., 1997, 97, 2341-2372; (e) J. Dong and J. X. Xu, Org. Biomol. Chem., 2017, 15, 836-844.

8 (a) S. Kramer and T. Skrydstrup, Angew. Chem., Int. Ed., 2012, 51, 4681-4684; (b) X. Huang, B. Peng, M. Luparia, L. F. Gomes, L. F. Veiros and N. Maulide, Angew. Chem., Int. Ed., 2012, 51, 8886-8890.

9 (a) M. Hamaguchi, N. Tomida and Y. Iyama, J. Org. Chem., 2007, 72, 1326-1334; (b) M. Anary-Abbasinejad and N. Rostami, J. Chem. Res., 2006, 589-590; (c) J. Azizian, M. R. Mohammadizadeh, A. A. Mohammadi and A. R. Karimi, Heteroat. Chem., 2005, 16, 259-262; (d) V. Nair, S. Bindu and L. Balagopal, Tetrahedron Lett., 2001, 42, 2043-2044; (e) T. Johnson, D. R. Cheshire, M. J. Stocks and V. T. Thurston, Synlett, 2001, 0646-0648; (f) P. Clawson and D. A. Whiting, Tetrahedron Lett., 1987, 28, 3155-3158; (g) M. Hamaguchi and T. Nagai, J. Chem. Soc., Chem. Commun., 1985, 190-191; (h) J. F. Gisch and J. A. Landgrebe, J. Org. Chem., 1985, 50, 2050-2054; (i) H. S. Gill and J. A. Landgrebe, J. Org. Chem., 1983, 48, 1051-1055; (j) H. S. Gill and J. A. Landgrebe, Tetrahedron Lett., 1982, 23, 5099-5102; (k) H. C. Berk, K. E. Zwikelmaier and J. E. Franz, Synth. Commun., 1980, 10, 707-710; $(l)$ H. Gotthardt, C. M. Weisshuhn and K. Dörhöfer, Chem. Ber., 1978, 111, 3336-3345.

10 (a) Y. Hayasi, M. Kobayasi and H. Nozaki, Tetrahedron, 1970, 26, 4353-4360; (b) M. Takaku, Y. Hayasi and H. Nozaki, Tetrahedron Lett., 1969, 10, 2053-2056.

11 M. Higo and T. Mukaiyama, Tetrahedron Lett., 1970, 11, 2565-2568.

12 (a) X. H. Li and J. X. Xu, Curr. Microwave Chem., 2017, 4, 339346; (b) X. H. Li and J. X. Xu, Tetrahedron, 2016, 72, 55155520; (c) X. H. Li and J. X. Xu, Curr. Microwave Chem., 2017, 4, 158-162; (d) L. B. Hu, Y. K. Wang, B. N. Li, D. M. Du and J. X. Xu, Tetrahedron, 2007, 63, 9387-9392; (e) D. Q. Yang and J. X. Xu, Curr. Microwave Chem., 2018, 5, 120-127.

13 (a) M. DellaGreca, S. Zuppolini, A. Zarrelli, M. R. Iesce and L. Previtera, Tetrahedron, 2013, 69, 4725-4730; (b) M. R. Iesce, R. Sferruzza, F. Cermola and M. DellaGreca, Helv. Chim. Acta, 2016, 99, 296-301.

14 S. Katayama, T. Watanabe and M. Yamauchi, Chem. Lett., 1989, 18, 973-976. 